\title{
Is Emotional Intelligence a Determinant Factor for Leader's Skills Development? Essential Literature Perspectives
}

\author{
Ştefan Gabriel BURCEA ${ }^{1}$ \\ Oana Matilda SABIE ${ }^{2}$
}

\begin{abstract}
The purpose of the paper is to emphasize the complexity of the concept and the difficulty of measuring emotional intelligence. There is a particular concern for highlighting the specific aspects of emotional intelligence role and contribution to the development of leadership skills. A brief review of the studies dealing with this topic is carried out within the article, precisely to demonstrate the utility of some future research directions in the field of emotional intelligence, like part of behavioural studies in organisations.
\end{abstract}

KEYWORDS: emotional intelligence, emotional intelligence models, leadership.

JEL CLASSIFICATION: $M 19$

\section{INTRODUCTION}

The emergence and development of the concept of Emotional Intelligence (EI) is due to Salovey \& Mayer (1990). The authors hypothesised a framework that describes a set of skills: relevant to appreciation and precise emotional expression, efficient emotional regulation and using feelings to motivate and plan one's life. In this way, they proposed that these two distinct mental processes, thinking and feeling, in fact, work together. Mayer, Salovey \& Caruso (2008) state that the central idea from which it started, is that some individuals have the capacity to rationalise and use emotions to improve their thinking more efficiently than others.

Since the beginning of the 1990s, EI has become a topic of interest in specialised literature, developing into a small industry in publishing, testing, education and consultancy in the early 2000s (Matthews, Zeidner and Roberts, 2004). In fact, Zeidner, Roberts and Matthews (2002). highlighted the broad concerns of the psychological literature in the field of Emotional Intelligence.

The literature on Emotional Intelligence has developed more and more over the last two decades, with numerous studies conducted that focus on human emotions. Therefore, it was concluded that Emotional Intelligence requires self-understanding, as considered by Goleman (2018). Emotions tend to affect our lives more and more, and as such, this type of intelligence can be developed throughout life by most people. The author discusses research aimed at analysing the human brain. Mayer and Geher (1996) debate how people manage to connect through their own emotions, and a survey sample of 321 participants demonstrated that people succeed in identifying the emotions of others, thus in turn, managing to understand themselves. Similarly, Schutte et al. (2001) analysed the influence of Emotional Intelligence on interpersonal relationships.

\footnotetext{
${ }^{1}$ Bucharest University of Economic Studies, Romania, stefan.burcea@amp.ase.ro, corresponding author

${ }^{2}$ Bucharest University of Economic Studies, Romania, oana.sabie@amp.ase.ro
} 
Beyond identifying and/or recognising emotions, Emotional Intelligence also involves managing one's own emotions and those of others. Mayer and Salovey (1993) note that Emotional Intelligence is a type of social intelligence, because it facilitates the regulation of individual emotions; they derive from people's expectations, which are in contradiction with what reality offers.

There are concerns in the literature regarding the correlation of Emotional Intelligence with the intellectual capacity of individuals. In general, a person's intelligence represents the level of intellectual ability that has often been used to predict academic and professional achievements. Mayer and Geher (1996) argue that although general intelligence indicates a person's general intellectual performance, it says little about the more specific intelligences that include it. Consequently, psychologists have sought to separate general intelligence into different types of intelligences, which are the repositories of more specific abilities, skills and behaviours. Of all these specific intelligences, the emotional one is correlated with leadership, Sechelariu (2012) highlighting the importance of the emotional dimension in the act of leadership.

Bar-on (2010) places the concept of Emotional Intelligence within the area of positive psychological study. Studies have shown that Emotional Intelligence has a significant impact on human performance, happiness, well-being, as well as on career exploration and personal development (Cote and Miners, 2006). All of these are key points in positive psychology, which is why the author considers that Emotional Intelligence should be included in this area. The interdisciplinary concept of Emotional Intelligence and dynamics of research in the field of artificial intelligence led to the development of theories on identifying the basic emotion of robots. Todoroi (2015) analysed the pros and cons regarding the implementation of ROBOEmotional Intelligence in society and promotes the process of implementing human emotions in ROBO-Emotional Intelligence. In fact, the European Union is the first community of countries, which in January, 2017 voted for the rights of robots to have passports - to be a civil entity in the Human-Robotic Society. The author argues that the following is necessary: clear regulations of emotion-based relationships in the future Human-Robotic society, its correlation with creative intelligence and the possibility to create ROBO-Emotional Intelligence starting from measuring the components of human emotions.

However, the literature approaches Emotional Intelligence from so many perspectives that it seems that this concept is invalid, in part because it is defined in too many ways (Locke, 2005).

\section{EMOTIONAL INTELLIGENCE MEASURES}

Emotional Intelligence (IE) is more important than Cognitive Intelligence (IQ), because no matter how many and varied tests exists to measure it, they are still limited and do not cover everything that emotional intelligence represents. If we talk about IQ, many common tests can be done to identify the IQ level a person has, but this is no longer the case with emotional intelligence, for which there is no standard test to measure it, with weak chances of ever designing such an indicator (Goleman, 2001).

When it comes to emotional intelligence, it is much more representative and is measured by various tests, much more complex. Although this is more difficult to quantify, several psychologists have discovered and devised several methods, such as: Mayer-Salovey-Caruso Emotional Intelligence Test (MSCEIT) which aims to test the emotional intelligence and performance of those to whom it is applied through various creative tasks, consisting of questions as objective as possible, in order to improve and solve any problems or tasks in which emotions are used (Sample, 2005). 
From the first research conducted on the topic of emotional intelligence, it was sought how it could be measured. In view of the above, the authors sought to find methods that would include what they considered useful to be identified, quantified and recorded, and then researched so that studies in this area would be as concrete as possible and close to reality. Thus, researchers began to design tests in different variants, with simple or complex questions, applied by age categories, or general tests to measure this type of intelligence.

Depending on how the test is applied, it can be: verbal and nonverbal. One of the first verbally methods used to measure emotional intelligence was the "Beth Israel Hospital Psychosomatic Questionnaire," which was applied to patients. They were asked certain questions, and their answer was quantified. This questionnaire was quite subjective, with low reliability, and in order to increase the degree of reliability a new test was introduced, which replaced the previous one, called: "Schalling - Sifneos Personality Scale", but which was limited by the way in which it was applied. (Salovey and Mayer, 1990)

When it comes to the nonverbal method, there have been several types of procedures, such as: "Affect Expression Rating Scale" and "Affective Communication Test". The first one was applied to students from different schools directly by teachers, and the second was intended for adults, through direct reporting. This nonverbal method had its limits, because many researchers, in the case of the verbal method, in addition to the answers to the questions, could also observe the facial expressions or gestures that the respondents made unconsciously when they were put in certain situations. This helped the information to be more accurate, but in a contradictory way, the response rate decreased. (Salovey and Mayer, 1990)

These methods have been followed by others, such as the method in which the individual selfadministers the test, also called the self-reporting or self-judgment scale, which is seen as the method that generates the lowest costs, takes little time, and which is also the easiest to administer. In contrast, this method is not reliable, because respondents can provide answers that they think are more accurate, which are not necessarily true, and on the other hand, there is the option when they do not really know their own qualities and can underestimated themselves (Brackett et al., 2011). For this reason, the authors recommend using the performance-based method of emotional intelligence rather than self-reporting.

In the literature we can identify in a first phase three theoretical models meant to measure in different ways emotional intelligence. These models are: the skill model, the foundations of which were laid by Mayer and Salovey; the factorial model, which was developed by the Israeli psychologist Bar-On, and, last but not least, the mixed model that was discovered by Goleman.

In this regard, Mayer and Salovey, in 1997, laid the foundations of the "Emotional Intelligence Model", which described emotional intelligence as having four branches: emotion perception, use of emotion to facilitate thinking, understanding emotions and emotion management. The first two represents the foundations of psychological processes, and the last two are part of those much more advanced psychological processes. Given these four components of emotional intelligence, the MSCEIT test has been developed and can be applied to adults. It tests this type of intelligence with questions from different categories, while MSCEIT YT- is the variant used by researchers to test the emotional intelligence of adolescents aged between 12-17 years. Both categories of tests need an average duration of 45 minutes to be completed (Brackett et al., 2011).

This measurement model is one that tries to penetrate the essence of emotional intelligence through the four branches, each based on different characteristics that manage to put individuals in various situations, so that the measurements would be as accurate as possible. In addition to these previously mentioned characteristics, there have been authors like Conte (2005) who have criticized this way of measuring emotional intelligence. One of the criticisms referred to the way in which the answers to the questions are quantified, because it 
is considered that the method used, the one through the scales with strict answers from 1 to 5 , limits the answers. The same can be said for the third part of this test, where respondents are given the answer options, with the possibility that none of them are consistent with the possible answers of individuals. Also, the way people react to various questions, from facial expressions, gestures, to the states they emanate, can no longer be observed, because it is a self-applicable test, both electronically and physically (Boyle et al., 2008).

At the international level, we can see the trend of expanding models and instruments for measuring emotional intelligence, from simple tests to more complex and detailed tests. One of these simple tests was Bar-On's Model of Emotional Intelligence, which started with a simple form and was later improved, becoming one of the three basic models of emotional intelligence. It first appeared in 1997, as a theoretical basis aimed to offer a better information about the "phenomenon" of emotional intelligence, and then became a way of measuring it (Bar-On, 2006).

The tool used to explain and develop this model is EQ-I and represents a set of 133 questions in form of short sentences, with a scale from 1 to 5 , where 1 means "very rarely or cannot be applied to me" and 5 it represents "very often true for me or truth about me." This test lasts 40 minutes and is used for people over 17 years. Later, a variant of 60 items was developed for young people from 8 to 16 years old, which takes about 15 minutes to complete. An advantage of this test is that it can be self-applied, which means that the application time is shortened, but also the interpretation of the data. The answers for this test are automatically generated by a software that works on the basis of matrices, such as tests for measuring IQ (Intelligent Quotient). The average scores of the EQ test show that the person is effective in terms of emotional and social intelligence. The higher the scores, the more able the person is to respond effectively to all daily challenges, and the low recorded scores of this test may suggest that the individual is prone to social problems, integration, is stressed, or has difficulty coping and controlling emotional intelligence (Bar-On, 2006).

In the Mayer and Salovey (1997) model, some authors (Boyle et al., 2008) suggested that one of its main disadvantages is that the method used to collect data is that of scales from 1 to 5 , which often limits the answers. Therefore, precisely so that the EQ-i test does not have errors and for the measurement to be as accurate as possible, a correction factor is used in the software that automatically adjusts the scores according to two indices: positive impression and negative impression; they have the role of reducing the distortive effects of responses (Bar-On, 2006).

The third model of emotional intelligence is Daniel Goleman's mixed model, which uses ESCI ("Emotional and social competence inventory") as a measurement method. This method had a first variant with 18 scales, consisting of 72 items, which was designed mainly only for certain types of individuals (key people in an institution, leaders). Then came up with a variant that can be applied to several types of individuals, from all social categories, reducing the number of items from 72 to 68, and also the scales from 18 to 12 (Hay Group, 2011)). ESCI can be applied in various institutions and organizations, from private to non-profit and public sector organizations and can be used as a method to improve the capacity of the workforce within them. Repeated application of this test in these institutions leads to a good method of assessing human resources. Goleman designed the test on four fundamental pillars: self-awareness, self-management, social awareness and social management or how we manage interpersonal relationships (Punia et al., 2015). Still, an interesting thing here is that Goleman does not recommend its use in selection, promotion or decisions salary (Hay Group, 2011). 


\section{EMOTIONAL INTELLIGENCE - PART OF LEADERSHIP SKILLS PATTERN}

Over the past decade, we have witnessed growing research on the importance of Emotional Intelligence for successful leadership. Underlying this theme is the unanimously accepted view that people, with high Emotional Intelligence skills are more likely to succeed in the workplace than people who are less emotionally intelligent.

What makes a leader successful has been a central question for researchers in the field of organisational management for decades. Carmeli (2003) identifies the extent in which managers with high Emotional Intelligence employed in the Israeli public sector develop positive skills, behaviours and results. Emotional Intelligence has been positively and significantly linked to job satisfaction, with leaders tending to develop an emotional attachment to their organisation and career. Carmeli's study showed that the degree of involvement in work is not related to the level of Emotional Intelligence, but rather, with seniority in the organisation. Furthermore, in comparison to employees in executive positions, managers with higher Emotional Intelligence better manage the balance between personal life and professional career.

Awareness of your own feelings as they arise is essential for anyone. Self-awareness translates into a high level of awareness of one's mood, but also of the thoughts associated with it. Şișcanu (2019) considers that the development of Emotional Intelligence increases knowledge and self-control, contributes to understanding feelings, thoughts, attitudes and motivations of other individuals, thus meaningful relations are created with other people, and we tend to establish meaningful connections with them. All these aspects are particularly essential in relation to the abilities, skills and behaviours of leaders.

Leaders with well-developed emotional capacities are more likely to be satisfied, and become more effective in relation to the teams they coordinate. They can better manage the emotions and behaviours that underlie their own productivity, as opposed to those who cannot control their emotional lives, considering that internal struggles negatively influence their ability to concentrate and think. George (2000) demonstrates that the way of thinking in combination with the mood of the leader can determine the behaviour in different contexts. For example, negative inner states lead to a more critical analysis of problems by the leader who relies more upon rational abilities in the moment. On the other hand, a good mood will result in a positive perspective of the problem and will enhance creativity. However, there is a risk that the consequences will be ignored. George concludes that in order to be an effective leader and appreciated by subordinates, you must have the highest possible level of Emotional Intelligence to know how to manage emotions and inner states, without affecting work processes.

Staff appraisal or professional performance appraisal is an activity that nowadays is largely widespread. If a few years ago, there was a tendency to apply intelligence tests as part of the selection process for employment, lately, assessing the level of Emotional Intelligence has become a major concern at the organisational level (Ashkanasy, 2002). In the context of leadership, the purpose of Emotional Intelligence is to achieve the goals of the coordinated team with minimum inter and intra-personal conflicts (Losîi, 2010). Even if the leader has enough knowledge and smart ideas, if they do not know themselves and fail to manage their emotions and feelings, they may encounter difficulties in trying to build relationships with members of their team.

Matthews, Zeidner, and Roberts (2004) believe that Emotional Intelligence includes verbal and non-verbal appreciation and expression of emotion, emotion regulation itself, and the use of emotional content in problem-solving. Therefore, testing the level of Emotional Intelligence of a leader can provide valuable information regarding their ability to process and adapt to affective information - essential for a person in a leadership position, who should be 
capable of providing stimulus and motivating team members. Ultimately, the fundamental ability of a leader, regarding Emotional Intelligence, consists of the ability to distinguish feelings and emotions, to label them, to include them in symbolic codes, to use them as a means of understanding, and guide the behaviour of people with whom they interact at work. Using social competence as an example, Scarr (1989) mentions that getting along well with others involves extraversion, self-confidence, low anxiety and social perception, characteristics absolutely necessary for a leader. Scarr further explains that although all of this correlates with intelligence, they are not intelligence. A leader's personality traits, such as extraversion, involves dispositions toward behaviours; leader intelligence, on the other hand, involves the ability to conduct oneself.

An individual with high Emotional Intelligence is able to develop dynamic leadership, good relationships with their superiors, subordinates and colleagues, and most importantly, they will have a high degree of personal satisfaction and success in the workplace. Rani (2015) analyses how Emotional Intelligence contributes to effective leadership, conducting a pilot research on 80 middle-management managers from 6 organisations. The study's findings suggested that developing skills and behaviours specific to Emotional Intelligence are essential for preparing managers' careers, as well as for personal success and fulfillment. Instead, Clarke (2010) investigates the effects of participating in an Emotional Intelligence development session, followed by team learning activities, on a sample of MBA students, and concludes that the development session alone has no effect. Participating in team learning activities has created stronger connections between team members, which really support the development of Emotional Intelligence. In fact, Petrovici (2014) supports the need for training programs in the field of Emotional Intelligence development. At the same time, Mattingly \& Kraiger (2019) perform a meta-analysis to demonstrate that Emotional Intelligence is instructible. Thus, the implementation of training programs on Emotional Intelligence is an effective investment in organisational development.

Toyota (2011) investigates the link between Emotional Intelligence and memory related to workplace events, and concludes that people with higher Emotional Intelligence remember all pleasant, unpleasant and neutral episodes. In contrast, people with lower Emotional Intelligence are more selective and remember only pleasant or unpleasant episodes; therefore, it would be preferable for leaders to have a high level of Emotional Intelligence. Similarly, Ryback (2011) uses an observation grid on certain people with different levels of Emotional Intelligence and concludes that participants with a higher coefficient of Emotional Intelligence discover different patterns or effects much faster than the average person, who would not discover them as quickly.

If in the past, members of management controlled, planned and inspected the general functioning of an organisation, today, the organisational leadership roles are, rather, to motivate and inspire employees, to encourage positive attitudes in the workplace and to develop a sense of contribution, belonging and importance with and amongst employees (Palmer et al., 2001). In response to the emergence of these new leadership requirements, training programs in the field of organisational leadership have been adapted to include a wide range of contemporary skills, including Emotional Intelligence.

It is interesting to look at how different leadership styles essentially condition the activities, processes and psychological phenomena within an organisation, and how leaders exercise their duties. Fodor (2009) conducts a sociological survey using 3 types of questionnaires on 30 formal leaders. The results of the study demonstrated that the performance of leaders who adopt a populist leadership style, on an Emotional Intelligence scale, are higher than those with an authoritarian leadership style. In the category of leaders with a high coefficient of Emotional Intelligence, positive correlations were obtained with emotional and behavioural coping strategies, and with constructive thinking, while in the group of subjects with a low 
coefficient of Emotional Intelligence, leaders with an authoritarian leadership style have categorical thinking and naive optimism.

The emotional skills of a leader have an overwhelming influence on the climate of an organisation, on the motivation of employees, on the customer relations. Thus, the development of the Emotional Intelligence models, detailing emotional skills, explaining the way in which they can be modeled, and in preparing tests to effectively assess these skills, become an important issue for an organisation's leadership. For example, Mi and Ramsay (2015) assess the relationship between Emotional Intelligence and transactional leadership within KPMG Vietnam. The aim of the research was to identify the most appropriate model for the management of the organisation and the extent to which Emotional Intelligence could influence the success of transactional management within the company. The results revealed the fact that KPMG Vietnam uses a combined model between the Goleman model and the Bar-On model.

In practice, it has been observed that no leader has had special skills in all Emotional Intelligence competencies. Even exceptional leaders excel in a limited number of skills. Suciu, Ghergheș and Petcu (2010) gives the example of an insurance company in the USA: agents deficient in terms of Emotional Intelligence, lack confidence, optimism, initiative and empathy, sold policies averaging $\$ 54,000$, while agents who had at least five of the eight competencies, according to the structure used, sold policies worth $\$ 114,000$.

The academic environment offers similar conclusions with respect to Emotional Intelligence and its influence on the outcomes of teachers and students. Accordingly, Marembo, Chinyamurindi and Mjoli (2018) investigated a sample of 220 teachers at a South African university to determine whether components of Emotional Intelligence, such as empathy, emotional expression, adaptability and self-control, influence the work performance of academics at the beginning of their careers. The results of the study confirmed that these competencies significantly predict work performance.

At the same time, Devi (2018) analyses the relationship between Emotional Intelligence and the academic results of students. The study's findings indicated that individuals with high Emotional Intelligence who are aware of their own emotions and those of others, are able to manage their feelings, and are capable of using these emotions to grow and develop their personality. Students with a solid knowledge of emotions are better able to focus on problemsolving skills, which develops their cognitive skills.

\section{CONCLUSIONS}

Studies conducted on Emotional Intelligence have marked the emergence of major research directions and different points of view, which indicates a growing interest in this field in the full development process. Despite the rapidly growing interest in Emotional Intelligence, measuring Emotional Intelligence using specific behaviours is still in a pioneering phase. As is inevitable for a new concept, Emotional Intelligence has received some criticism lately. In particular, using a range of available tools and, for the most part, poorly validated tools as a basis for analysis, the validity of constructing Emotional Intelligence has been questioned.

The area of Emotional Intelligence requires experienced researchers interested in contributing to the development of the field on a solid basis, refining the assessment based on the skills and abilities of Emotional Intelligence, and enriching it with a behavioural approach. Undoubtedly, it becomes necessary to study in depth the predictive validity of Emotional Intelligence in evaluating results obtained in various fields of activity (education, health, social relations, etc.).

The relationship between Emotional Intelligence and life satisfaction, the quality of interpersonal relationships and professional success clearly deserve the additional attention of 
researchers. While preliminary tests of Emotional Intelligence are promising, there is an urgent need for further psychometric development. When the relationship between Emotional Intelligence and related life criteria is fully substantiated and understood, a logical subsequent step for research will be to develop adaptive training and remediation programs that help strengthen the consolidation of emotional skills and improve the behaviours of an Emotionally Intelligent person.

\section{ACKNOWLEDGEMENT}

This work was supported by a grant of Bucharest University of Economic Studies for institutional projects, project number PI - 2019 - IEIPA - 1838/30.07.2019, project title „Assessing the Impact of Emotional Intelligence on the performance of employees in the public and private sectors/Evaluarea Impactului Inteligenței Emoționale asupra Performanței Angajaților din sectoarele public și privat” (IEIPA)

\section{REFERENCES}

Ashkanasy, N.M. (2002). Studies of cognition and emotion in organisations: Attribution, affective events, emotional intelligence and perception of emotion. Australian Journal of Management, 27(1_suppl), 11-20.

Bar-On, R. (2006). The Bar-On model of emotional-social intelligence (ESI). Psicothema, 18 (suppl), 13-25.

Bar-On, R. (2010). Emotional Intelligence: An Integral Part of Positive Psychology. South African Journal of Psychology, 40(1), 54-62.

Boyle, G., Matthews, G. and Saklofske, D. (2008). The SAGE Handbook of Personality Theory and Assessment: Personality Measurement and Testing. London: SAGE Publications.

Brackett, M., Rivers, S. and Salovey, P. (2011). Emotional Intelligence: Implications for Personal, Social, Academic and Workplace Success. Social and Personality Psychology Compass, 5(1), 88-103.

Carmeli, A. (2003). The relationship between emotional intelligence and work attitudes, behavior and outcomes: An examination among senior managers. Journal of Managerial Psychology, 18(8), 788-813.

Clarke, N. (2010). Developing emotional intelligence abilities through team-based learning. Human Resource Development Quarterly, 21(2), 19-138.

Conte, J.M. (2005). A Review and Critique of Emotional Intelligence Measures. Journal of Organizational Behavior, 26(4), 433-440

Cote, S. and Miners, C.T.H. (2006). Emotional intelligence, cognitive intelligence, and job performance. Administrative Science Quarterly, 51(1), 1-28.

Devi, D. (2018). The Relationship between Emotional Intelligence and Academic Achievement among Intermediate Students. IOSR Journal of Business and Management, 20(4), 30-35.

Fodor, I. D. (2009). Inteligența emoțională și stilurile de conducere. Iași: Lumen. 
George, J.M. (2000). Emotions and Leadership: The Role of Emotional Intelligence. Human Relations, 53(8), 1027-1055.

Goleman, D. (2018). Inteligența emoțională (Ediția a IV-a). București: Curtea Veche.

Hay Group (2011). Emotional and social competency inventory (ESCI) - A user guide for accredited practitioners. Retrieved January 20, 2020, from http://www.eiconsortium.org/pdf/ESCI_user_guide.pdf

Locke, E.A. (2005). Why emotional intelligence is an invalid concept. Journal of Organizational Behavior, 26(4), 425-431.

Losîi, E. (2010). Inteligenţa emoţională şi succesul profesional al lucrătorilor bancari. Psihologie. Pedagogie Specială. Asistenţă Socială, 20, 1-12.

Marembo, M., Chinyamurindi, W. T. and Mjoli, T. (2018). Emotional intelligence influences on the work performance of early career academics: An exploratory study. Journal of Psychology in Africa, 28(5), 407-410.

Matthews, G., Zeidner, M. and Roberts, R.D. (2004). Emotional intelligence: science and myth. New Bakerswille: MIT press.

Mattingly, V. and Kraiger, K. (2019). Can emotional intelligence be trained? A metaanalytical investigation. Human Resource Management Review, 29(2), 140-155.

Mayer, J. D. and Geher, G. (1996). Emotional intelligence and the identification of emotion. Intelligence, 22(2), 89-113.

Mayer, J.D. and Salovey, P. (1993). The Intelligence of Emotional Intelligence. Intelligence, 17(4), 433-442.

Mayer, J.D., Salovey, P. and Caruso, D.R. (2002). MSCEIT ${ }^{\mathrm{TM}}$ Mayer-Salovey-Caruso Emotional Intelligence Test. Multi-Health Systems, 3-11.

Mayer, J.D., Salovey, P. and Caruso, D.R. (2008). Emotional intelligence: New ability or eclectic traits?, American Psychologist, 63(6), 503-517.

Mi, T.Q.H. and Ramsay, B. (2015). Emotional Intelligence and Transactional Leadership performance. Case study - KPMG Vietnam. International Journal of Business and Social Research, 5(6), 33-43.

Palmer, B., Walls, M., Burgess, Z., Stough, C. (2001). Emotional intelligence and effective leadership. Leadership \& Organization Development Journal, 22(1), 5-10.

Punia, N., Dutta, J. and Sharma, Y. (2015). Emotional Intelligence: A Theoretical framework. International Journal of Scientific \& Engineering Research, 6(5), 967-1006.

Rani, M.S. (2015). Emotional Intelligence - A Model for Effective Leadership, Competency and Career Growth. Indian Journal of Science and Technology, 8(S4), 240-246.

Ryback, D. (2011). Putting Emotional Intelligence To Work. Successful Leadership Is More Than IQ. New York: Routledge.

Salovey, P. and Mayer, J.D. (1990). Emotional Intelligence. Yale University, 185-202.

Sample, J. (2005). Mayer-Salovey-Caruso Emotional Intelligence Test ${ }^{\mathrm{TM}}$. Toronto: MultiHealth Systems Inc. 
Scarr, S.W. (1989). Protecting general intelligence: Constructs and consequences for interventions. In R. L. Linn (Ed.), Intelligence: Measurement, theory, and public policy: Proceedings of a symposium in honor of Lloyd G. Humphreys (p. 74-118). University of Illinois Press.

Sechelariu, M. (2012). Emotional intelligence and leadership. Journal of Criminal Investigations, 5(1), 183-190.

Suciu, S., Ghergheș, V. and Petcu, D. (2010). Emotional Intelligence and Leadership. Anale. Științe Economice. Timișoara, 16, 549-555.

Șişcanu, S. (2019). Emotional Intelligence: Is It about Life - or Life Itself? Revista de Teorie și Practică Educațională Didactica Pro, 4-5(116-117), 102-105.

Todoroi, D. (2015). Temperament Aspects of Emotional ROBO-Intelligence Creation Process. Economy Informatics, 15(1), 35-48.

Toyota, H., 2011. Individual differences in emotional intelligence and incidental memory of words. Japanese Psychological Research, 53(3), 213-220.

Zeidner, M., Roberts, R.D. and Matthews, G. (2002). Can Emotional Intelligence Be Schooled? A Critical Review. Educational Psychologist, 37(4), 215-231. 